\title{
ÉLITES URBANAS: LAS POLÍTICAS COMERCIALES Y DE MERCADO COMO FORMAS DE PREVENCIÓN DE CONFLICTOS Y DE LEGITIMACIÓN DEL PODER (LA VEDA DEL VINO EN CUENCA EN LA BAJA EDAD MEDIA)
}

\begin{abstract}
José Antonio Jara Fuente*
Control y cohesión social, legitimación del poder: la ciudad medieval se nos muestra generalmente como un campo de batalla abonado para las continuas disputas que surgen entre pecheros y caballeros; contiendas que no admiten más que vencedores y vencidos, o, a lo más, respiros, treguas con que reunir nuevas fuerzas para el combate. En este sentido, la ciudad medieval parece un mundo aparte, una estructura social sui generis que opera más procesos de control social (sobre la base de un poder, institucionalizado o no, y de unas alianzas coyunturales y unas clientelas más o menos amplias), que mecanismos de cohesión social y de legitimación del poder capaces si no de evitar el conflicto, sí de atenuarlo o resolverlo mediante acuerdos que limitan la capacidad de actuación de todos los actores (frente al maniqueísmo de vencedores y vencidos, todos comparten pérdidas y ganancias). Y, sin embargo, es claro que la estructura social de la ciudad medieval no es más que un fenómeno amplificado de un más amplio sistema de relaciones sociales feudales ${ }^{1}$, no un cuerpo extraño en el seno de éstas; y que dichos mecanismos de resolución de conflictos, entre otros, deben encontrarse presentes en mayor o menor medida.

Precisamente, una de estas fórmulas viene dada por las políticas comerciales y de mercado que restringen la "libre" actuación del individuo, encorsetándola mediante un conjunto de ordenanzas encaminadas, se dice, a procurar el bien común ${ }^{2}$. Este es el

\footnotetext{
* Centro de Estudios Históricos (CSIC-Madrid)

1. ABRAMS, Ph., 1978:9-33;y ESTEPA DIEZ, C., 1990: 467-506.

2. En este marco se inscribe la política permanente de fijación de los precios de los bienes de consumo (no sólo alimentos), general en todo el urbanismo medieval. Una política que se acompaña de mandatos más puntuales, cuando las condiciones del mercado o la "necesidad" de la población así lo exigen. He seleccionado tres acuerdos adoptados a lo largo de 1467, que lo ilustran suficientemente.

Así, el 20 de Marzo el regimiento prohíbe que el vino, que no se ha terminado de vender en día de mercado, sea luego vendido fuera de éste por perjudicar la venta del vino que cosechan los vecinos: Archivo Municipal de Cuenca (AMC.), Libros de Actas (LL.AA.), legajo (leg.) 198, expediente (exp.) 1, folio
} 
caso de la veda del vino. A través de ella intentaré mostrar cómo las élites urbanas se sirven de la misma como mecanismo de control y cohesión social, en última instancia, de legitimación de su poder, con el fin de asegurar su reproducción como grupo en el poder y como un vehículo más de extensión del poder elitista a todo el marco urbano.A este fin, me centraré en el análisis de la ciudad de Cuenca, a la que tomo como modelo.

\section{LA POLÍTICA COMERCIAL CONCEJIL}

Es bien sabido cómo el concejo castellano, sobre todo en el centro y sur de la Península, controla una amplia área rural (alfoz o Tierra), dependiente de aquél; y cómo, en la Baja Edad Media, estos concejos ejercen poderes señoriales sobre dicha área rural. Este carácter señorial hace que la política comercial de la ciudad castellana se ejerza, en principio, en provecho de la misma y no de su distrito rural, de la Tierra. Como en general para todo el urbanismo medieval, esa política comercial se asienta sobre tres pilares fundamentales: $1^{\circ}$.) garantizar a la ciudad el abastecimiento de artículos de primera necesidad; $2^{\circ}$.) actuar con criterios monopolistas, buscando colocar a la población urbana en una posición favorecida en el sistema de los intercambios; y $3^{\circ}$.) desarrollar medidas de evidente naturaleza proteccionista, que aseguren el acceso al mercado de los productos locales, limitando la competencia de los bienes importados de otras áreas.

En Cuenca, el Fuero (cuya redacción más probable se sitúa hacia 1190, aunque algún autor la retrasa hasta mediados del siglo XIII) ${ }^{3}$ otorgaba a la ciudad un día de mercado los Martes; aunque, con posterioridad, en 1466, el rey Enrique IV, a instancias del obispo de la ciudad, Don Lope de Barrientos, y del noble Don Andrés de Cabrera, concedió otro día de mercado franco el Jueves. El concejo, fundamentalmente a lo largo del siglo XV, desarrollará una amplia normativa tendente a garantizar el funcionamiento óptimo de dicho mercado, en el sentido de los tres criterios enunciados más arriba. En el desenvolvimiento de dicha normativa: $1^{\circ}$.) otorgó la exención de impuestos a los productos vendidos en día de mercado; $2^{\circ}$.) trató de evitar en lo posible la presencia de mercaderes extranjeros (aunque a fines del siglo XV su participación ya era un hecho); y $3^{\circ}$.) tendió a concentrar en la ciudad la actividad comercial, mediante el ejercicio de su autoridad señorial.

Una autoridad señorial que se plasmó en unos mecanismos coactivos a través de los cuales forzó a las aldeas de 5 leguas alrededor de Cuenca a vender sus productos exclusivamente en el mercado urbano, situado dentro del recinto murado ${ }^{4}$; obligó a los sexmos de la Tierra, cuando las circunstancias lo exigieron, a abastecer en exclusiva a la ciudad, e incluso extendió dicha política, en la medida en que le resultó factible, a

(fol.) 22r. El 31 de Octubre ordena que nadie adquiera zapatos para llevarlos fuera de la ciudad, y su término, con el fin de abaratar los precios de dicho artículo en la ciudad (AMC., LL.AA., leg. 198, exp. 1, fol. 89r).Y, finalmente, el 21 de Noviembre dispone que las panaderas no vendan pan a los vecinos con hacienda superior a $10.000 \mathrm{mrs}$., "porque se venda a la gente de poca fasienda"; aquéllos deberán hacerlo cocer en sus casas (AMC., LL.AA., leg. 198, exp. 1, fol. 97r).

3. BARRERO GARCÍA,A.M., 1982: 41.58.

4. Ordenanza de 5 de Abril de 1458; citada en CABAÑAS GONZÁLEZ, M.D., 1985: 1.701-1.728. 
los lugares de señorios; y, finalmente, prohibió las transacciones comerciales en los arrabales (extramuros de la ciudad), a todo lo largo del siglo $\mathrm{XV}^{6}$.

Así pues, mediante incentivos de naturaleza fiscal y coactiva, el regimiento busca garantizar un abastecimiento de artículos de primera necesidad y materias primas, para la industria local, suficiente y, en ocasiones, monopolista. Un proteccionismo que no debe ser entendido únicamente en el sentido de salvaguardar los intereses de la propia élite. Es cierto que, mediante un abastecimiento seguro de artículos de primera necesidad a precios razonables, el regimiento se asegura un nivel de salarios bajo que, a su vez, garantiza una producción manufacturera a precios competitivos (desde luego en términos pre-industriales), lo que facilita o consolida su expansión comercial (interregional o internacional). No obstante, rara vez las decisiones políticas son unidimensionales. Pues, si bien es cierto que estas políticas comerciales restrictivas favorecen a la élite, también lo es que benefician al conjunto de la población urbana.

Este es, como señalábamos al comienzo del artículo, el caso de la restricción comercial urbana por antonomasia, la veda, es decir la prohibición de vender en la ciudad, durante un cierto tiempo más o menos prolongado, artículos producidos fuera de su territorio. Nosotros nos centraremos en la veda del vino. Esta se establece durante el invierno, período en el que se impone la venta en la ciudad únicamente del vino que producen sus ciudadanos; esto es, se prohíben las importaciones de vino foráneo.

LAS ÉLITES URBANAS: Procesos DE ESTRUCTURACIÓN INTERNA

¿Actúa la élite estas políticas comerciales con un sentido oligárquico del poder? Es decir, ¿imponen las élites estas políticas buscando su propio beneficio económico?

Tradicionalmente se ha venido afirmando este carácter oligárquico del poder que ejercen las élites urbanas porque, desde el centro del poder municipal, persiguen sus propios fines de clase $e^{7}$ Ello resulta en un análisis muy simplista de los problemas del poder pues no hay grupo social que no lo ejerza en su propio provecho. Lo que debemos cuestionarnos es si de dicho ejercicio del poder se desprenden utilidades tangibles para los grupos sociales dominados; beneficios que conduzcan a éstos a no contestar la posición dominante de la élite.Y, aún más, debemos preguntarnos por el funcionamiento mismo de la élite, por los procesos de estructuración que se verifican en el interior de este grupo social y que conducen a su segmentación en subgrupos

5. Es el caso del sexmo de Arcas, jurisdicción de Cuenca, al que una ordenanza de 1462 impuso el abastecimiento de trigo a la ciudad. En cuanto a los lugares de señorío, sirva de ejemplo la ordenanza de 20 de Marzo de 1467, por la que se mandó que los vecinos de señorío que compraran en el mercado de Cuenca trigo, cebada o centeno, por cada fanega llevaran una arroba de vino de la cosecha de los vecinos de Cuenca: (AMC., LL.AA., leg. 198, exp. 1, fol. 22r).

6. CABANAS GONZÁLEZ, M.D., 1985: 1.701-1.728. Sobre el mercado urbano en Cuenca, véase también GUERRERO NAVARRETE, Y. y J.M. SANCHEZ BENITO, 1994: 189 y ss.

7. La cuestión no es pacífica, aunque, en general, los historiadores interesados en concejos tienden a inclinarse por ese carácter oligárquico del ejercicio del poder por los grupos urbanos dirigentes. Sobre el particular, merece la pena detenerse en el conjunto de síntesis que, en II CONGRESO DE ESTUDIOS MEDIEVALES: 1990, se dedica al análisis de los fenómenos urbanos en las Coronas de Aragón y Castilla; especialmente los trabajos de Ios profesores GONZÁLEZ JIMÉNEZ, M., 1990: 237-260; ESTEPA DIEZ, C., 1990: 467-506; y MONSALVO ANTÓN, J.M., 1990: 359-413. 
sociales según su mayor o menor proximidad al centro real de la dominación en la ciudad; una estructuración que afecta a la forma en que cada subgrupo participa de las ventajas del poder.

Sabemos cómo en Castilla, desde el Ordenamiento de Alcalá de 1348, los oficios municipales son reservados a los caballeros de cuantía, es decir, a aquellos ciudadanos que disfrutan de un determinado nivel de renta, variable para cada ciudad. Al mismo tiempo, el Ordenamiento de 1348 divide los cargos públicos urbanos en dos grandes bloques: por una parte los cargos de regimiento y, por otra, los restantes oficios municipales. Se dibuja, así, un modelo de gobierno en el que el verdadero poder urbano se ejerce desde el regimiento, configurándose los otros oficios como un auxilio a los regidores en sus tareas de gobierno.

Si obtenemos las conclusiones apropiadas de este modelo de gobierno urbano resulta que no podemos hablar de élite urbana en un sentido global, sino que debemos profundizar en la forma en que los individuos que se integran en la élite participan en el poder. No es este lugar para discutir los problemas que plantean los procesos de estructuración que operan en el seno del grupo dirigente; sin embargo, si no tenemos presentes estos procesos, y la consiguiente estructuración interna en el grupo elitista, el análisis de los mecanismos de cohesión social y de legitimación del poder, de que ésta se sirve, perdería en riqueza conceptual (no olvidemos que las más peligrosas contestaciones al centro de la dominación no proceden del común sino de aquellos subgrupos próximos al centro del poder pero que no participan directamente de éste). En cualquier caso, bien que sintéticamente, podemos distinguir:

$1^{\circ}$. Una élite urbana de poder: El pequeño grupo de linajes urbanos que, gracias a su mayor riqueza y mejores relaciones con la monarquía y la nobleza, ha logrado, a lo largo de los siglos XIV y XV, entrar en el regimiento.

$2^{\circ}$. Una élite urbana de participación: El más amplio grupo de linajes urbanos que, por su menor riqueza y relaciones con otras esferas superiores de poder, ha sido únicamente capaz de acceder al desempeño de oficios municipales auxiliares. Por supuesto, desde que un linaje ingresa en la élite urbana de participación, su aspiración es ascender socialmente, hacerse más rico y poderoso, y acceder a la élite urbana de poder. Esto será posible a lo largo del siglo XIV y primera mitad del XV; pero, a partir del último tercio de la centuria del cuatrocientos, aproximadamente, al hacerse hereditarios los oficios de regimiento, el paso de la élite urbana de participación a la élite urbana de poder se hace excepcional y sólo individuos con muy buenas relaciones con la monarquía o la alta nobleza lo lograrán.

De esta forma, durante la Baja Edad Media se verifica en el seno de la élite urbana un proceso de jerarquización interna que conduce a la división del grupo social elitista en los dos subgrupos mencionados: la élite urbana de poder, que es la que realmente ejerce el poder urbano; y la élite urbana de participación, que ejerce oficios auxiliares/menores de poder, y disfruta de las ventajas que ofrece su cercanía al verdadero centro de la dominación (a la élite urbana de poder). 


\section{¿EJERCICIO OLIGÁrquico DEL PODER?. LA VEDA DEL VINO}

Retomando ahora la pregunta que nos hacíamos antes, ¿a quién benefician estas políticas comerciales, a la élite urbana como un todo, a alguno de los subgrupos en que ésta se jerarquiza internamente o, incluso, al conjunto de la población urbana?

Observemos los problemas que plantea la veda del vino.

Dicha veda se aplica en Cuenca desde $1329^{8}$, extendiéndose el período de vigencia de la misma hasta el consumo total de las existencias locales e intensificándose las medidas inspectoras del mercado para evitar el fraude. Así, por ejemplo, en 1460 se sellan los cueros que contienen el vino, para controlar las importaciones posteriores; y en 1467 se obliga a quienes no son vecinos del término y quieren comprar cereal, a adquirir por cada fanega de pan una arroba de vino 9 . Así pues, se trata, en todos los casos, de medidas tendentes a liquidar las existencias del vino local ${ }^{10}$.

El caso de Cuenca no es extraordinario; en general todas las ciudades castellanas imponen similares restricciones con el fin de favorecer la venta de sus vinos, sobre todo en casos, como el de Cuenca, en los que el vino es de mala calidad y se prefiere el consumo de caldos procedentes de otras áreas. En este sentido, los casos de Burgos (ciudad de realengo, como Cuenca) o Talavera (ciudad bajo el señorío del

8. Fecha en que el concejo dicta la correspondiente ordenanza, que es aprobada por el rey el mismo año. Vid GUERRERO NAVARRETE, Y. y SÁNCHEZ BENITO, J. M., I 994: 198; y CABAÑAS GONZÁLEZ, M.D., 1985.

9. AMC., LL.AA., leg. 198, exp. 1, fol. 22r.

10. Merece la pena reseñar, siquiera sea en extracto, la ordenanza de 12 de Enero de 1468 (AMC., LL.AA., leg. 198, exp. 2, fols. 3v-4v).

En ella se ordena la veda del vino por causa de la abundante cosecha habida y para favorecer a los herederos y bodegueros de Cuenca. Y se establece:

I. Que no entre vino en la ciudad, sus arrabales y en una legua a su alrededor, desde el próximo 22 de Enero, so pena de perder el vino, los cueros y $200 \mathrm{mrs}$. por carga, de los cuales un tercio será para el que lo tomare o le acusare, un tercio para los regidores y el alcalde que le juzgue, y un tercio para la ciudad [estas penas se reproducen en las condiciones de la veda que siguen].

II. Para garantizar el abastecimiento de pan, quienes lo traigan a vender los Jueves de mercado podrán vender una carga de vino por cada carga de pan; para evitar fraudes, registrarán el pan y vino ante un regidor o alcalde y el escribano.

III. Prohíben a bodegueros, mesoneros, taberneros o cualquier otro comprar el vino que se traiga los Jueves con el pan.

IV. La veda del vino foráneo comenzará el 1 de Febrero. Los taberneros que la infrinjan perderán todos los cueros y vasijas, llenos y vacíos, que posean en la taberna o en otro sitio.

V. Si los taberneros tuvieran aún vino foráneo el 1 de Febrero, deberán registrarlo ante alcalde o regidor y escribano, comprometiéndose a no venderlo durante la veda.

VI. Las licencias para meter vino se darán en concejo, como en los años pasados, y pagará el beneficiario al arrendador de las penas de la veda $1 \mathrm{mrs}$. por cántaro.

VII. Que se saquen las penas de la veda en arrendamiento, y su arrendador pueda tomar el vino metido y se quede con el tercio de las penas que corresponde al tomador.

VIII. Que los clérigos beneficiados de la iglesia mayor guarden la concordia hecha entre la ciudad y dicha iglesia.

La ordenanza es suficientemente ilustrativa del interés que muestra el concejo por el control de la veda; el énfasis que se pone en controlar la actividad de los taberneros, y las graves penas que recaen sobre ellos, en su caso, se explica por sí solo: al fin y al cabo, son ellos los encargados de poner el vino a la venta y resulta más sencillo establecer fuertes medidas de control y punición sobre éstos, evitando que, en última instancia, alguien pueda "saltarse" el sistema de licencias, pues, aun así, todavía deberá encontrar un tabernero dispuesto a correr el riesgo de vender el vino entrado ilegalmente. 
arzobispo de Toledo) son paradigmáticos. En Burgos la producción vitivinícola es escasa y, por lo general, de ínfima calidad, y la salida de este vino hacia las capas sociales más pobres es relativamente segura. Aquí el problema no se centra en el establecimiento de períodos de veda, sino en abastecer a la ciudad de vinos de calidad suficiente a precios razonables, toda vez que el vino no es sólo objeto de consumo alimentario sino que también se emplea en las labores de tinte de los paños manufacturados en la ciudad. La posición de Burgos como gran importador de vino, y su poderío económico, fue aprovechada por el concejo para transformar su aparente situación de debilidad en su propio provecho. Al configurarse como un gran centro de importación de vino, capaz de absorber la producción total de las villas próximas, Burgos pudo imponer a los concejos aledaños, y sus productores, sus propias condiciones comerciales, controlando las negociaciones mediante la amenaza de ordenar el boicot de sus caldos ${ }^{11}$.

En Talavera, donde la producción de vino es ampliamente excedentaria, sólo los vecinos de la ciudad están autorizados a vender su vino en la misma. Dado que el mercado urbano no era capaz de absorber la producción, el concejo talaverano desarrolló estrategias más agresivas, acudiendo a una política de señorialización de la Tierra y de los concejos limítrofes similar a la de Burgos. Se prohíbe la entrada de vinos foráneos; se autoriza a los ciudadanos de Talavera a vender su vino por toda la Tierra dependiente de la ciudad; en las zonas de nueva repoblación, dependientes del concejo, se prohíbe la plantación de viñas, creando así mercados para los vinos talaveranos; $y$, finalmente, se llega a acuerdos comerciales con concejos límitrofes, ventajosos para el de Talavera, mediante los cuales la ciudad obtiene la imposición de vedas de vino en aquéllos, durante las cuales sólo los vecinos de Talavera están autorizados a venderlo, en evidente perjuicio de los vecinos de dichos con$\operatorname{cejos}^{12}$.

Ahora bien, ¿son los miembros de la élite urbana los primeros interesados en el establecimiento de estas vedas porque son también los mayores propietarios de viñas y, por tanto, los mayores productores de vino en sus ciudades? Alrededor de esta cuestión vamos a plantear tres grandes cuestiones:

$1^{\circ}$. Los criterios de inversión económica de la élite urbana.

$2^{\circ}$. La proyección del capital urbano sobre la tierra.

$3^{\circ}$. Las licencias que se conceden para introducir vino foráneo en la ciudad durante el período de veda.

11. Boicot que Burgos ejecutó contra la villa de Madrigal en 1461 y contra la de Roa en 1465. Vid GUERRERO NAVARRETE, Y., 1986: 354-357 y notas 52 y 53.

12. A mediados del siglo XV el concejo de Talavera inicia la repoblación de un área marginal de su territorio, La Jara, prohibiendo expresamente la plantación de viñas. En 1426 y 1446 el concejo acuerda con el monasterio de Guadalupe la autorización del uso de los pastos de Talavera por los vecinos de La Puebla de Guadalupe, dependiente del monasterio, obteniendo, a cambio, un nuevo mercado para sus vinos vía una veda del vino en este lugar, en favor de los talaveranos, durante los meses de Febrero a Mayo. Similares tratos realiza con el arzobispo de Toledo y las villas, dependientes de éste, de Villafranca de la Puente del Arzobispo y de Alcolea de Tajo.

Vid SUAREZ ÁLVAREZ, M.J., 1982: 97-99, 102-103 y 106-107. 
En todo caso, no podemos generalizar, sino analizar lo que sucede en cada marco urbano.

$1^{\circ}$. Los criterios de inversión económica de la élite urbana: En Cuenca, a lo largo del siglo XIV se constata un abandono del cultivo de la vid que sólo comienza a recuperarse lentamente a partir de $1400^{13}$. En Burgos, donde ya hemos informado de la escasez de dicho cultivo y de la mala calidad de su vino, y debido a ello, a finales del siglo XIV y a lo largo del siglo XV se producirá un paulatino proceso de transformación de cultivos, abandonándose la vid por el cereal.Aquí, tanto las instituciones eclesiásticas como los miembros de la élite urbana proceden a dicha transformación en sus propiedades y, para garantizarse individualmente un abastecimiento de vino de calidad, adquieren censos o propiedades vinícolas en áreas extraburgalesas de mejor producción $^{14}$.

Debemos recordar, además, que Burgos es caput castellae, el corazón económico de la Corona castellana, y que obtiene su riqueza del comercio a larga distancia con Francia, Flandes e Inglaterra. Y que en Cuenca la principal fuente de riqueza (y, por tanto, fundamental objeto de inversión económica) viene dada por la ganadería y el comercio de la lana, bien natural o manufacturada; una lana de gran calidad que se exporta a Italia, vía Valencia, y a la zona del Canal de La Mancha, vía Burgos ${ }^{15}$. En ambas ciudades los miembros de la élite urbana no destinan su capital precisamente a invertirlo en un producto, la vid, de escasa calidad en su región y que proporciona pequeños márgenes de beneficio.

Por el contrario, en ciudades como Talavera o Segovia, donde los miembros de la élite no disponen, aparte de la ganadería, de otras actividades económicas susceptibles de reportarles importantes ingresos, su proyección hacia la producción de cereales y vino es mayor, y aquí la veda sí resulta en beneficio principal de la élite urbana,y sobre todo de la élite urbana de poder ${ }^{16}$.

$2^{\circ}$. La proyección del capital urbano sobre la tierra: En Burgos ya hemos visto que la élite urbana procede, en el siglo XV, a la transformación de sus cultivos, pasando de la vid al cereal. ¿Qué sucede en Cuenca? La élite urbana de poder desarrollará una política tendente a la construcción de pequeños señoríos, sobre todo en el área de la Sierra ${ }^{17}$. Una política exitosa o no, según los casos; pero que, desde un punto de

13. SÁNCHEZ BENITO, J.M., 1994: 133.

14. Quizás el ejemplo más significativo sea el que nos proporciona el regidor Alonso de Villanueva, quien, a su muerte en 1520, poseía propiedades vinícolas en la villa de Pampliega por valor de 1.259.100 mrs., más unos $36.000 \mathrm{mrs}$. por el vino que tenía allí encubado.

Vid CASADO ALONSO, H., 1987: 127-138.

15. Cfr. el ya clásico trabajo de IRADIEL MURUGARREN, P., 1974.

16. En Segovia la lana es de ínfima calidad y se reserva para un comercio de carácter regional y de beneficios económicos reducidos. Por otra parte, en lo que hace a la veda del vino, sí parece claro el favorecimiento de los intereses de la élite urbana, en concreto de la élite urbana de poder, a juzgar por las continuas quejas del común de ciudadanos a lo largo del siglo XV por la mala calidad del vino que se veía obligado a consumir.

Vid MARTÍNEZ MORO,J., 1985: 158-159; y ASENJO GONZÁLEZ, M., 1986.

17. Algunos intentos se producirán también entre miembros de la élite urbana de participación, rápidamente desautorizados y combatidos por la élite de poder. 
vista económico, busca la ampliación de sus intereses ganaderos. La inversión económica más rentable sigue siendo la lana ${ }^{18}$.

Por su parte, la élite urbana de participación, sobre todo desde el último cuarto de siglo, sitúa una parte importante de su capital en la tierra. Por esta vía, adquiere un número importante de pequeñas propiedades dispersas por la ciudad de Cuenca y su Tierra. Entre ellas se encuentran numerosas propiedades vinícolas. ¿El hecho de convertirse en mediana propietaria de tierras de vid, hace a la élite urbana de participación la primera interesada en el mantenimiento de la veda del vino? La respuesta no es enteramente positiva.Y ello por la misma naturaleza jurídica de los contratos a través de los cuales la élite adquiere dichas tierras. Se trata, por lo general, de ventas por juro de heredad, en las que el vendedor mantiene la posesión (e incluso derechos de transmisión) a cambio del pago de un censo anual al adquirente; el vendedor, por tanto, puede cultivar la tierra libremente $\mathrm{y}$ vender, también libremente, su producción ${ }^{19}$.

Tal es el caso del intento llevado a cabo por Martín de Soria sobre el término de La Losilla, que dará lugar a un conflicto que, iniciado a mediados de la década de 1460 , no culminará hasta Septiembre de 1467 , y que terminará involucrando en el mismo a la monarquía, tanto a través de su representante en Cuenca, el corregidor Pedro de Salas, como de mandatos hechos por el mismo rey. Finalmente, el término tornará al concejo, resultando Martín de Soria desposeído (AMC., LL.AA., leg. 198, exp. 1, fols. 38r-40r y 41r-v).

No sucede, sin embargo, lo mismo cuando se trata de entradas ejecutadas por miembros de la élite urbana de poder. En estos casos los pleitos, para recuperar los términos ocupados ilegalmente, se prolongan en el tiempo, sucediéndose las sentencias y mandatos de desocupación, por lo general sin mayores consecuencias. Hasta el punto de que, a fines del siglo XV, los Reyes Católicos aún han de intervenir para desautorizar estas entradas, prohibiendo, el 27 de Abril de 1493, a Fernando del Castillo, Iñigo López de Mendoza, conde de Tendilla, Iñigo López de Mendoza, conde de Priego, Alonso de Fonseca, obispo de Cuenca, Juan Hurtado de Mendoza, Pedro Carrillo de Albornoz, Pedro de Barrientos, comendador de la villa de Huélamo, Leonor de Portocarrero, viuda de Alarcón, y a cuantos poseen lugares en Cuenca, que cercen los lugares comunes de la ciudad y su tierra; entre miembros de la nobleza territorial local, observamos también referencias a integrantes de la élite urbana de Cuenca, como Fernando del Castillo o Pedro de Barrientos (AMC., LL.AA., leg. 10, exp. 30, citado por MOYA PINEDO, J., 1977: 34.

18. Sobre usurpaciones, ejecutadas tanto por nobles, campesinos, como élites urbanas, ver MORETA, S. y A. VACA, 1982; CABRERA MUÑOZ, E., 1976; CABRILLANA, N., 1969.

No sólo disponemos de información sobre los intereses ganaderos de los miembros de la élite a través de lo que nos revela esta "política" de ocupaciones. Otro tipo de noticias, como las que nos proporcionan las denuncias por robo de ganado, el arrendamiento de dehesas o de las tablas de carnicería de la ciudad, resultan imprescindibles. Así, entre los miembros de la élite de poder, a mediados del XV, los Fernández de Chinchilla o los Alcalá (AMC., LL.AA., leg. 197, exp. 3, fols. 29v-30r; leg. 198, exp. 1, fol. 15v y exp. 2, fol. 5v; y leg. 205, exp. 1, fols. 69r-69v), y los Çahorejas a comienzos de la centuria (AMC., LL.AA., leg. 185, exp. 5, fol. 9v; publicado por JIMÉNEZ MONTESERIN, M. (dir.), 1994). Las referencias a miembros de la élite de participación son, así mismo, numerosas; baste citar a los Molina, o los Losillo, Orduña, Manzano, Lázaro o Valdecabras (AMC., LL.AA., leg. 205, exp. 2, fols. 34v-35r y fols. 37r-v; leg. 204, exp. 3, fols. 104v-105v; leg. 198, exp. 1, fols. 61v; y leg. 195, exp. 2, fol. 17r).

19. Son escasos los datos de que disponemos para el siglo XV, pero las tendencias que se apuntan a comienzos del siglo XVI (el primer protocolo notarial que se conserva es de 1503) no debieron ser muy distintas a las de la última mitad de la centuria anterior.

En estos primeros años de la centuria del quinientos, las ventas por juro de heredad constituyen la norma, no sólo en lo que se refiere a las transmisiones de inmuebles rurales, sino también urbanos.

Es el caso de la venta por juro de heredad que Catalina Sánchez, mujer de Andrés Sánchez de Torralba, difunto, y Fernando de Torralba, su hijo, vecinos de Collados (lugar de Cuenca), realizan en favor de Juan de Ortega, notario de Cuenca, de un censo de 2 fanegas de pan que imponen sobre un molino harinero de Collados, cerca del río, sobre unas casas de morada que tiene en el mismo lugar; así mismo, le venden el molino, las casas, un majuelo y media yunta de heredad cercanos a aquél. Todo por 1.500 mrs., ya recibidos; acuerdan pagar el censo el día de San Miguel de Septiembre (AHPC, Sec. Protocolos, caja P-1, Juan del Castillo, años 1503-1504, fol. 206v-209v). 
De los problemas que hemos analizado, se desprende que, en ciudades del tipo de Burgos o Cuenca, la élite urbana (tanto la de poder como la de participación) no es beneficiaria directa de la veda del vino ${ }^{20}$. ¿Qué sucede con el tercer problema?

$3^{\circ}$. Las licencias que se conceden para introducir vino: Durante el período en que se impone la veda del vino, observamos en Cuenca cómo en diversas ocasiones el regimiento (la élite urbana de poder) da licencia a un ciudadano para introducir vino en la ciudad; un vino que no procede de la Tierra de Cuenca y cuya venta en la ciudad, durante la veda, está prohibida. ¿Utiliza la élite el sistema de licencias para evitar la veda y así cortocircuitar su propia política comercial?

Veamos lo que se puede dedudir del contenido de las licencias documentadas a lo largo del siglo XV:

$1^{\circ}$. Los miembros de la élite urbana de poder apenas resultan solicitantes-beneficiarios de estas licencias ${ }^{21}$.

$2^{\circ}$. El mayor número de licencias se concede en favor de los miembros más importantes de la élite urbana de participación.

O el de Juan de Ayala e Inés de Chinchilla, su mujer, vecinos de Cuenca, quienes venden al honrado Diego de Madrid, también vecino, por juro de heredad unas casas con su heredad de tierra de pan llevar, viñas, solares, heredad de pan trillar, que tienen en el lugar de Arcos de la Sierra, jurisdicción de Cuenca, por precio de 22.000 mrs., ya pagados (AHPC, Sec. Protocolos, caja P-1, Juan del Castillo, años 1503-1504, fol. 221v-223v).

O, finalmente y para el medio urbano, el de Alonso de Becerril, el mozo, hijo de Alvaro de Becerril, y Mari Quijada, su mujer, vecinos de Cuenca, quienes venden por juro de heredad a la noble señora Doña Ana Condulmario, mujer del noble caballero Don Luis Pacheco, señor de Villarejo de Fuentes y vecino de Cuenca, 5 pares de casas de morada que tienen: en Carretería, extramuros de Cuenca, junto al mesón de Juan de Alcocer, otras que dan a la calle, y otras en que vive Elvira López; todo, con cargo de un censo anual por cada par de casas de 3 mrs./año, pagaderos por San Juan de Junio (AHPC, Sec. Protocolos, caja P-1, Juan del Castillo, años 1503-1504, fol. 229r-231v).

20. Algo similar sucede en Palencia, aunque sobre la base de unos fundamentos socio-económicos distintos. Aquí, los miembros de la élite de poder actúan unas políticas de ambigüedad relativa, a través de las cuales, al tiempo que procuran ostensiblemente servir los intereses del señor de la ciudad (el obispo), colaboran con el común en su intento de reducir paulatinamente el contenido de la autoridad señorial de aquél, siempre con el objetivo de aumentar su propia parcela de poder. Los intereses ganaderos de la élite chocarán a todo lo largo del siglo XV con los aprovechamientos agrícolas del común, en un término, como el de Palencia, reducido, que dificulta la creación de amplias explotaciones. Vid, FUENTE PEREZ, M.J., 1989, especialmente sobre los conflictos surgidos entre ganadería y agricultura, 288-293, y sobre el vino, 275-282.

21. Como veremos, el siguiente ejemplo resulta suficientemente ilustrativo. El 13 de Marzo de 1467 comparecía ante el regimiento el bachiller Alonso González de Toledo (miembro de uno de los linajes principales de la ciudad), y solicitaba licencia para vender un poco de vino, que aún le sobraba de su cosecha, a algún tabernero, y que se mandara a éste que vendiera sólo el que él le diera. El regimiento respondió mostrándose conforme, aunque señalando que otros vecinos habían solicitado lo mismo y se les había denegado debido a la preocupación que tenían los regidores porque los taberneros pudieran cometer fraude, vendiendo dicho vino y vino foráneo durante la veda. Finalmente acordaban que si el bachiller designaba un tabernero que diera seguridad de que no vendería vino de fuera, se lo autorizarian.

Conocida la noticia, comparecieron inmediatamente Alonso Ruiz de Huete,Alonso Bordallo y Juan de Concejo, vecinos, solicitando la misma licencia que se había dado al bachiller.

El regimiento acuerda otorgársela, con las mismas condiciones que al primero. Y, seguidamente y de oficio, acuerda, así mismo, conceder la licencia a Juan Ferrández de Chinchilla, regidor y vecino, a quien se le había denegado con anterioridad (AMC., LL.AA., leg. 198, exp. 1, fol. 15r). 
$3^{\circ}$. Un porcentaje pequeño, pero significativo, de estas licencias se otorga a algunos recién llegados a la élite urbana de participación ${ }^{22}$.

$4^{\circ}$. Aproximadamente una mitad de las licencias autorizan la entrada en la ciudad de vinos procedentes de otras áreas de la Tierra de Cuenca que no son las inmediatas a la ciudad. Estos vinos no son considerados foráneos y el ciudadano conquense está autorizado a venderlos; la licencia, en estos casos, no es sino un control más sobre la procedencia del vino.

$5^{\circ}$. El conjunto de licencias concedidas es tan reducido, en comparación con el conjunto de la población, que, cuantitativamente resulta despreciable ${ }^{23}$.

La constancia del sistema de licencias parece indicar un cierto cumplimiento de la normativa de la veda por parte de la élite urbana de poder ${ }^{24}$. En ello redunda el hecho de que la licencia es concedida bajo la condición de no poder vender el vino, cuando foráneo, durante la veda o de dedicarlo al consumo personal del beneficiario.

A la vista de todo lo manifestado hasta ahora, ¿podemos afirmar que la élite urbana instrumentaliza estas políticas en su propio beneficio?, ¿actúa con criterios oligárquicos? Gonnard ${ }^{25}$, refiriéndose al ejercicio del poder en la Edad Media y retomando concepciones tomistas del mismo, afirmaba que "...la autoridad tiene que ser directiva, encaminada al bien general y no al interés de quien la posee...". ¿Leyeron a Santo Tomás nuestras élites urbanas? En mi opinión, la cuestión debe ser afrontada desde otra perspectiva. Lo importante no es que el poder fuera ejercido, o no, con criterios éticos por las élites urbanas. Lo verdaderamente importante es que éstas, en el ejercicio del poder, desarrollan algunas políticas que reportan indudables beneficios a los grupos sociales dominados. La aceptación por los dominados de estas políticas conduce a la aceptación del poder como un todo, a la legitimación del mismo y, consiguientemente, a la legitimación del uso del poder por parte de las élites urbanas, fin último de estos procedimientos de control social que ponen aquéllas en marcha. En palabras de Pierre Bourdieu, en toda sociedad los dominados contribuyen a su propia dominación, siendo las disposiciones que les inclinan a esta entrega, entre otras, el efecto incorporado de la misma dominación ${ }^{26}$.

22. Es el caso, por ejemplo, de Francisco de Molina,Alonso Manuel, Gil de Jábaga, Ferrando de Cuenca, o Ferrand Sánchez de Teruel, entre los miembros prominentes de la élite de participación; o de Francisco Redondo, Sancho de Uclés y Martín de Soria, entre los recién llegados. Todas las licencias les fueron concedidas a lo largo del invierno de 1468, con la condición de no vender el vino cuando foráneo (AMC., LL.AA., leg. 198, exp. 2, fols. 9r, 10r, 16v, 17v, 19r, $24 \mathrm{v}$ ).

23. Así, por ejemplo, AMC., LL.AA., leg. 187, exp. 5, fols. 29v-30r; leg. 188, exp. 3, fols. 1v y 3r-4v; leg. 189 , exp. 4, fols. 35r-v, y exp. 6, fols. 38r-39r; leg. 190 , exp. 3, fol. $18 \mathrm{v}$; leg. 194, exp. 3, fol. $42 \mathrm{v}$ y exp. 4 , fols. $22 \mathrm{r}, 27 \mathrm{v}-28 \mathrm{r}, 99 \mathrm{v}-100 \mathrm{r}$.

24. No obstante la preocupación que, en ocasiones, manifiesta el regimiento ante las transgresiones que se producen, tanto más graves cuanto que se originan en algunos de sus miembros.

Así, el 17 de Abril de 1461, ante la constancia de no respetarse la veda del vino y de que algunos regidores la entorpecen autorizando a ciertas personas a introducirlo en la ciudad, acuerdan prohibir toda entrada salvo para el obispo, Juan Hurtado y justicias y regidores, precisando que las demás licencias habrán de ser extendidas mediante cédula firmada por dos regidores con cargo de regimiento y ante el escribano del concejo (AMC., LL.AA., leg. 195, exp. 2, fols. 15r-v).

25. GONNARD, R., 1961:29-30.

26. BOURDIEU, P., 1989: 12. 
Basil Bernstein ${ }^{27}$, analizando la influencia que la pertenencia a una determinada clase social y subcultura ejercen sobre el comportamiento y el aprendizaje de los individuos, afirma que cuanto más abajo en la escala social, mayor es la resistencia al aprendizaje y educación formales, y mayor es también la preferencia por procesos cognitivo-descriptivos más que analíticos; resultando todo ello en una función de la estructura social del estrato social en cuestión. Es decir, y por lo que a nosotros interesa, ello implica que los grupos sociales inferiores están funcionalmente predispuestos a observar el poder desde una óptica unidimensional de beneficio/perjuicio personales. Significa que son menos capaces, que otros grupos sociales, de observar el poder como un todo, y que tienden a legitimarlo, a no contestarlo, en la medida en que las decisiones de poder que afectan a su pequeño mundo les benefician; y a la inversa.

En este sentido, para la élite urbana las políticas de intervención comercial se configuran, entre otras cosas, como una función de control social de los grupos sociales inferiores.

En este marco analítico, el sistema de vedas articula, así mismo, una función de control social de más largo alcance. Como hemos visto, la veda favorece, al menos teóricamente, a los habitantes de la ciudad en perjuicio de los de la Tierra; y a través de la veda se ponen en funcionamiento mecanismos de señorialización de la Tierra por la ciudad. Siguiendo este razonamiento, la veda actúa en un un doble sentido:

$1^{\circ}$. Asegura a los pequeños y medianos propietarios urbanos de viñas la venta de sus vinos en el mercado urbano.

$2^{\circ}$. Contribuye a elaborar un ideal comunitario urbano de señorío sobre la Tierra: Hasta el más humilde de los ciudadanos de Cuenca es consciente de que, como habitante de la ciudad, es un privilegiado frente a los habitantes de la Tierra, que han de soportar las consecuencias de su dominación por la ciudad ${ }^{28}$.

Consiguientemente, la veda se configura como una función de control social doble para las élites urbanas, $y$ en concreto para las élites urbanas de poder:

$1^{\circ}$. Como coacción-prohibición positiva:A través de la imposición de la veda la élite de poder reconstruye una imagen ideal del poder en cuanto que ejercido en el interés general, desde luego de los habitantes de la ciudad.

Así mismo, como todo acto de prohibición conlleva, al menos en potencia, su opuesto, un acto de transgresión, la élite urbana de poder positiviza las transgresiones de la veda al legalizarlas vía la concesión de licencias.Al situar la trans-

27. BERNSTEIN, B., 1971: 23-25.

28. Es el caso de las ceremonias que bermanan comuna urbana y contado en Italia con ocasión de los festivales que, en la primera, tienen por centro al santo patrón, la Virgen María como protectora de la ciudad, $\mathbf{u}$ otras festividades importantes, como el Corpus Christi. La presencia, y ofrendas, del contado en estos festivales urbanos, manifiesta los vínculos que unen a la ciudad y la tierra. Pero se trata de unas ligazones muy particulares, pues esta participación se reviste usualmente de mecanismos coercitivos: la ciudad impone la presencia del contado así como las ofrendas que ha de aportar (el incumplimiento se sanciona generalmente con multas pecuniarias, aunque, en ciudades como Ascoli, se prevé incluso la declaración de rebeldía y el consiguiente castigo). El contado participa en estos actos, pues, prestando una suerte de homenaje, en un sentido claramente feudal.

Vid CHITTOLINI, G., 1990: 69-80. 
gresión en positivo, a través de la licencia, la élite urbana de poder está eliminando, al menos en términos ideales, la posibilidad de que se ejecuten actos de oposición al poder. En este sentido, toda transgresión ilícita de la veda se configuraría como un acto de contestación al poder.

Finalmente, el hecho de que la concesión de las licencias quede al arbitrio de la élite urbana de poder (pues es el regimiento quien las autoriza), tiene una doble implicación:

a) Por un lado, los miembros de la élite urbana de participación, o aquellos individuos que comienzan a elevarse socialmente de entre el común, al pretender participar en este sistema de privilegios (las licencias), se colocan en la posición de tener que aceptar el sistema de poder existente como un todo... o la élite urbana de poder no les permitirá disfrutar de dichas ventajas.

b) Por otro lado, la élite urbana de poder utiliza el sistema de licencias para clientelizar a los grupos o subgrupos sociales inferiores ${ }^{29}$. Pero, al mismo tiempo, el desarrollo por la élite urbana de poder del sistema de licencias la obliga a ponerlo en ejecución. El sistema de licencias actúa al modo de los incentivos selectivos, enunciados por Olsson: la concesión de la licencia se configura como un premio; la denegación, como un castigo. Pero, una vez creado el sistema de licencias, la élite urbana de poder no puede prescindir de él, al formar ya parte de los procesos de retroalimentación positiva del sistema urbano de poder $^{30}$.

$2^{\circ}$. Una segunda función de control social viene dada por el hecho de que estas políticas comerciales se manifiestan como un mecanismo que facilita la cohesión política de la sociedad urbana: Estas políticas comerciales, y más concretamente la veda, unen a los habitantes de la ciudad en un proyecto común de ciudadanía cuya manifestación más visible es la separación política entre ciudad y distrito rural, y la dominación que la primera ejerce sobre el segundo. Todos los habitantes de la ciudad, desde el más poderoso al más humilde, forman parte del aparato de dominación de la ciudad sobre la Tierra; en última instancia, más pobres o más ricos, todos son señores.

29. Son numerosos los casos en que esta clientelización aparece en forma más que evidente:

El 6 de Marzo de 1467 el regimiento autoriza a Luis de Fuente a traer 150 cántaros de vino que tiene de ciertas rentas, y ello a petición de Luis de Chinchilla, integrante de la élite urbana (AMC., LL.AA., leg. 198, exp. 1, fol. 12v).

El 11 de Marzo de 1467 dan licencia a Elvira Ferrández, mujer de Alonso de Ración, vecina de Cuenca, para traer a la ciudad 30 cántaros de vino para las bodas de su hija y de su sobrina. Y, en parecido sentido, el 2 de Febrero de 1468 autorizan a García de Belmonte, albardero, para meter 2 cargas de vino en la ciudad y venderlas, por razón de que lo necesita para casarse (AMC., LL.AA., leg. 198, exp. 1, fols. 13v y 12r).

Finalmente, acaso el ejemplo más ilustrativo, la licencia que concede el regimiento el 23 de Marzo de 1468 a Alvaro de Cuenca para que pueda vender su vino, porque «está descalabrado e ha mester dinero» (AMC., LL.AA., leg. 198, exp. 2, fol. 9v).

30. Sobre el análisis de los términos del intercambio que se operan en este tipo de procesos, y la adhesión a las reglas del juego que se imponen los actores en el desenvolvimiento de aquéllos, vid CROZIER, M., 1964; BLAU, P. y J.E. SCHWARTZ, 1984: 173-174; y DI TOMASO, N., 1980. 
Nuevamente por esta vía la élite urbana obtiene la sanción, la legitimación del poder que ejerce por el común.Al incorporarse éste al sistema de dominación, siquiera sea en su proyección sobre la Tierra, la aceptación de este elemento de dominación del sistema conlleva la no contradicción con el sistema urbano de poder como un todo.

Por supuesto, como ya hemos manifestado, esta doble función de control social persigue una misma finalidad: la legitimación del poder que la élite urbana de poder ejerce sobre la ciudad y la Tierra. Es a través de éstos, y otros mecanismos, que la clase dominante se procura respiros, concordias, alianzas; en última instancia, el disfrute más o menos pacífico de la posición alcanzada en el esquema urbano de poder.

\section{CONCLUSIÓN}

Frente a la tentación, general, de analizar estas políticas comerciales y de mercado como simples mecanismos de regulación de la oferta y la demanda, encaminados a conseguir el abastecimiento de la ciudad de artículos de primera necesidad, y puestos en ejecución en interés del bien público (como continuamente se repite en los libros de actas de cada concejo); deberíamos profundizar en lo que dichas políticas significan en orden a la consecución de la cohesión social en la ciudad, la no contestación a, e incluso la complicidad con el sistema de dominación por parte de los dominados, y, en última instancia, la legitimación del poder alcanzada, precisamente, con el concurso activo de quien lo soporta.

En todo caso, conviene tener en cuenta que, si el modelo analítico que presentamos es trasladable a otros ámbitos concejiles, los mecanismos de cohesión social y de legitimación del poder no han de ser necesariamente idénticos, pues variarán en función de la forma en que se verifiquen los procesos de estructuración interna de la élite y de las condiciones económico-sociales imperantes (como hemos mostrado, sirviéndonos de lo que se conoce para concejos como Cuenca y Burgos, o Talavera y Segovia); por lo que se hace necesario un análisis en profundidad de lo que acontece en otras áreas concejiles. Estudio que, hoy por hoy, todavía se encuentra en sus comienzos. 


\section{BIBLIOGRAFIA}

ABRAMS, Ph., 1978.

"Towns and Economic Growth: Some Theories and Problems", en ABRAMS, Ph. y E.A. WRIGLEY (eds.), Towns in Societies. Essays in Economic History and Historical Sociology, Cambridge University Press, 9-33.

ASENJO GONZÁLEZ, M., 1986.

Segovia. La ciudad y su tierra a fines del medievo, Segovia.

BARRERO GARCÍA,A.M., 1982.

"El proceso de formación del Fuero de Cuenca (Notas para su estudio)", en Cuenca y su territorio en la Edad Media, Actas del I Simposio Internacional de Historia de Cuenca (Cuenca, 5-9 de Septiembre de 1977), Consejo Superior de Investigaciones Científicas, Madrid-Barcelona.

BERNSTEIN, B., 1971.

Class, Codes and Control, 1, Theoretical Studies towards a Sociology of Language, Londres.

BLAU, P. y J.E. SCHWARTZ, 1984.

Crosscutting Social Circles. Testing a Macrostructural Theory of Intergroup Relations, Orlando.

BOURDIEU, P., 1989.

La noblesse d'Etat. Grandes Ecoles et esprit de corps, París.

CABAÑAS GONZÁLEZ, M.D., 1985.

"Ciudad, mercado y municipio en Cuenca durante la Edad Media (siglo XV)", en La ciudad bispánica durante los siglos XIII al XVI, II, Actas del Coloquio celebrado en La Rábida y Sevilla, Madrid, 1701-1728.

CASADO ALONSO, H., 1987.

Señores, mercaderes y campesinos. La comarca de Burgos a fines de la Edad Media, Junta de Castilla y León, Valladolid.

CABRERA MUÑOZ, E., 1976.

"Usurpación de tierras y abusos señoriales en la sierra cordobesa durante los siglos XIV y XV", Actas del I Congreso de Historia de Andalucía.Andalucía Medieval, II, 33-80.

CABRILLANA, N., 1969.

"Salamanca en el siglo XV: nobles y campesinos", Cuadernos de Historia, 255-295.

CHITTOLINI, G., 1990.

"Civic Religion and the Countryside in Late Medieval Italy", en DEAN,T. y Ch. WICKHAM (eds.), City and Countryside in Late Medieval and Renaissance Italy. Essays Presented to Philip Jones, Londres, 69-80.

II CONGRESO DE ESTUDIOS MEDIEVALES, 1990.

Concejos y ciudades en la Edad Media bispánica, 25-29 de Septiembre de 1989, Fundación Sánchez Albornoz, Madrid.

CROZIER, M., 1964.

"Pouvoir et organization", en Arcbives Européennes de Sociologie/European Journal of Sociology, V, 1, 52-64.

DITOMASO, N., 1980.

"Organizational Analysis and Power Structure Research", en DOMHOFF, G.W. (ed.), Power Structure Research, Beverly Hills-Londres, 1980, 255-268. 
ESTEPA DÍEZ, C., 1990.

"El realengo y el señorío jurisdiccional concejil en Castilla y León (siglos XII-XV)", en II CONGRESO DE ESTUDIOS MEDIEVALES, 467-506.

FUENTE PÉREZ, M.J., 1989.

La ciudad de Palencia en el siglo XVAportación al estudio de las ciudades castellanas en la Baja Edad Media, facsímil de la Tesis, Universidad Complutense de Madrid.

GONNARD, R., 1961.

Historia de las doctrinas económicas, Madrid.

GONZÁLEZ JIMÉNEZ, M., 1990.

"Ciudades y concejos andaluces en la Edad Media: gobierno urbano", en II CONGRESO DE ESTUDIOS MEDIEVALES, 237-260.

GUERRERO NAVARRETE, Y., 1986.

Organización y gobierno en Burgos durante el reinado de Enrique $N$ de Castilla, 14531476, Universidad Autónoma de Madrid (Colección Antiqua et Mediaevalia, $\mathrm{n}^{\circ}$. 6), Madrid.

GUERRERO NAVARRETE, Y. y J.M. SÁNCHEZ BENITO, 1994.

Cuenca en la Baja Edad Media: Un sistema de poder, Diputación Provincial de Cuenca (Serie: Historia, $\mathrm{n}^{\circ} .9$ ), Cuenca.

IRADIEL MURUGARREN, P., 1974.

Evolución de la industria textil castellana en los siglos XIII-XVI, Salamanca.

JIMÉNEZ MONTESERIN, M. (dir.), 1994.

Actas Municipales del Ayuntamiento de Cuenca. I. Años 1417, 1419 y 1420, Ayuntamiento de Cuenca.

MARTÍNEZ MORO, J., 1985.

La tierra en la comunidad de Segovia. Un proyecto señorial urbano (1088-1500), Universidad de Valladolid.

MONSALVO ANTÓN, J.M., 1990.

"La sociedad política en los concejos castellanos de la Meseta durante la época del regimiento medieval. La distribución social del poder", en II CONGRESO DE ESTUDIOS MEDIEVALES, 359-413.

MORETA, S. Y A.VACA, 1982.

"Los concejos urbanos núcleos de señoríos corporativos conflictivos. Aproximación a las relaciones entre oligarquía urbana y campesinos en Zamora y su tierra, siglo XV", Agricultura y Sociedad, 343-365.

MOYA PINEDO, J., 1977.

Corregidores y regidores de la ciudad de Cuencà desde 1400 a 1850, Cuenca.

SÁNCHEZ BENITO, J.M., 1994.

Las tierras de Cuenca y Huete en el siglo XIV.Historia económica, Universidad de CastillaLa Mancha, Murcia.

SUÁREZ ÁLVAREZ, M.J., 1982.

La villa de Talavera y su tierra en la Edad Media (1369-1504), Universidad de OviedoDiputación Provincial de Toledo (Serie: Publicaciones del Departamento de Historia Medieval, $\mathrm{n}^{\circ} .10$ ), Oviedo. 
